\title{
Perspectives on Diversity in the Military: A Comparison between Belgium and the Netherlands
}

\author{
Rudy Richardson ${ }^{1}$, Delphine Resteigne ${ }^{2}, \&$ Mathias Bonneu \\ ${ }^{1}$ Stoas University of Applied Sciences, Netherlands Defence Academy, The Netherlands \\ ${ }^{2}$ Chair of Sociology, Royal Military Academy, Belgium \\ Correspondence: Rudy Richardson, NLDA, De La Reijweg 120, P.O. Box 4818 BB Breda, The Netherlands. E-mail: \\ ral.richardson.01@nlda.nl
}

Received: February 18, 2014

Accepted: March 17, 2014

Available online: May 22, 2014

doi:10.11114/ijsss.v2i3.421

URL: http://dx.doi.org/10.11114/ijsss.v2i3.421

\begin{abstract}
In a comparative way, this article analyses the dimensions of cultural diversity in the military context of Belgium and the Netherlands, and describes how these organizations may be comparable or differ in their acceptance towards cultural diversity. To do this, we start by stressing the importance of dealing with cultural diversity in both the Belgian and Dutch military, and by depicting the main cultural traits of the two countries regarding major cultural groups. Multicultural attitudes, Muslim attitudes and Acculturation orientations are the main theoretical concepts we used in this research to elaborate 'the perspectives on cultural diversity' in the Belgian and Dutch military. We compared the results of a similar quantitative survey conducted in the Belgian and Dutch military. We discuss how cultural diversity is perceived among both organizations and the dimensions on which the subgroups tend to differentiate themselves.
\end{abstract}

Keywords: cultural diversity, acculturation, multicultural attitudes, Muslim attitudes

\section{Introduction}

Cultural diversity refers to the questions whether different cultures respect each other's cultural (ethnic, gender, racial, religious and socioeconomic) differences in a situation, institution, or group. It is still regarded as an important issue in society in general and in the Armed Forces in particular. At the societal level, a greater degree of cultural diversity can be a liability for civic engagement and social connectedness so that more homogeneous communities could arise (Quillan, 1995; Liu, 2007). Regarding the Armed Forces, firstly, most western politicians often requires their Forces to reflect society regarding gender, socio-economic status/education level, religion, sexually orientation and ethnic culturally origin or, at the latest, to be open and tolerant regarding various forms of diversity (Winslow \& Dunn; Dansby \& Landis, 2007; Bosman, Richardson \& Soeters, 2007) This "discrimination-and-fairness" perspective is characterized by: "a belief in a culturally diverse workforce as a moral imperative to ensure justice and the fair treatment of all members of society", (Ely \& Thomas, 2001). Secondly, it has been argued that cultural diversity in the Armed Forces may increase the effectiveness in humanitarian missions and the cooperation between the military and local civilians in (former) conflict areas, but also for military personnel working in multinational operations (Miller \& Moskos, 1995; Bosman, 2008; Soeters \& Van der Meulen, 2007; Resteigne \& Soeters, 2010). Since 2001, Armed Forces were mostly deployed in Islamic countries like Bosnia, Iraq and Afghanistan. This requires their employees to effectively deal with eastern (most of them Islamic) cultures in the interaction with civilian local organizations and governments, in training local governmental armies and police, in coordination and support of elections, and in humanitarian support of the local population. Earlier research showed that, when deployed with gender, religious and ethnic diversity, unions are better able to take into account the values and cultural habits of the society and its population, and to communicate more easily with the local population.

To attract staff from different backgrounds, it seems of utmost importance that the military adopt an open mind towards cultural diversity (Dansby, Stewart \& Webb, 2001). Negative attitudes may cause majority members in the company to put pressure on minority members to adjust themselves to the dominant culture of the company. Ethnic minorities, religious minorities as well as women still do not always feel comfortable in the military and feel accepted as person. These minorities have generally the feeling that they have to completely adapt to the dominant culture and habits (e.g., practical jokes) and they experience difficulties in educational opportunities and possibilities for professional growth in 
the military organization. On the other hand, in some countries, like the United States, military organizations can also be an important channel of social integration. Following a process of 'institutionally established' social mobility, lower ranks are able to reach upper positions and to mix with other minority groups (Moskos \& Butler, 1995).

In some ways, it seems that the integration of newcomers in a host country and the integration of minorities in a military organization is a two-way process: on the one hand, the military organization needs to create or adapt its policies so that possible barriers in order 'to feel at home' can be removed and, on the other hand, minorities must follow the military organizational values and guidelines (Scoppio, 2009). In general the "quality of the diversity climate" is an important factor to feel comfortable or not in military organizations (Richardson, Op den Buijs, Van der Zee, 2011). In this context, we studied the diversity climate in the Dutch and Belgium Armed Forces.

In this article, we have focused our analysis on those two countries because, on the military side, they are already working in close collaboration since several years, notably in the Navy. However such cooperation is not really new as the history of the two countries is closely intertwined. With similar budgetary issues, both countries are increasing their cooperation, among other for the training of their military personnel. Facing important problems of recruitment, they also both have tried to be more open to less traditional categories of personnel and, among them, to ethnic minorities. In this article, we will look more carefully at the way followed by both nations in order to integrate them and, when comparing the two, how organizational policies can have a major impact in those so-called "uniformed organizations". This leads to the following central research question in our study:

What are differences between the attitudes towards cultural diversity of military and civilian employees of the Dutch and the Belgian Armed Forces?

In this study, we focus on the 'multicultural' dimension of cultural diversity, i.e, the attitude towards ethnic groups and Muslims in particular. We start, firstly, with elaborating the theoretical framework we used to study the different attitudes in both military organizations. We, secondly, will describe the external environment of the Belgian and the Dutch military organizations and by depicting the main cultural traits of the two countries regarding the multicultural dimension of cultural diversity. Furthermore, thirdly, we will describe which methods and instruments we used in our study. Fourthly, we will present the most interesting results of our study and will, lastly, end with some conclusions and discussion.

\section{Multicultural and Muslim attitudes}

As we argued above, it is important for military organizations that majority members have a positive attitude towards cultural diversity. This is mainly the case for organizations which are facing important problems of recruitment and, as we have seen in Afghanistan, who are operating in culturally complex environments (Manigart \& Resteigne, 2013). A military organization which has an open mind towards cultural diversity can lead to minority members feeling more accepted, attracts more of them and, at the long run, increases the effectiveness in missions and civil-military cooperation (Van der Meulen \& Soeters, 2007). Cox (1993) defines cultural diversity as: "The representation, in one social system, of people with distinctly different group affiliations of cultural significance". Those differences can be physical (e.g. skin color), biological (e.g. gender), religious (e.g. Muslim) or stylistic (e.g. clothing). In the present study, we will focus on the 'multicultural dimension' of cultural diversity. We operationalize this 'multicultural dimension' into three main concepts, i.e., the attitudes towards 'Multiculturalism', the 'Muslim attitude'and the 'acculturation orientation' (Bosman, Richardson \& Soeters, 2007; Richardson, Op den Buijs \& van der Zee, 2011).

The main concept of interest here concerned multicultural attitudes. This can be defined as the attitude of employees towards the (integration of) ethnic minorities in an organization (Berry \& Kalin, 1995; Berry, Poortinga, Segall \& Darren, 1992; Bosman, Richardson \& Soeters, 2007; Richardson, Op den Buijs \& Van der Zee, 2011). Cooperation and integration among different ethnic groups improves when this attitude is positive, while a negative attitude puts a restraint on mutual relations and therefore can become a source of conflict. According to Arends-Tóth and Van de Vijver (2003), Multicultural attitude (MCA) can be divided into two dimensions. On the one hand, a positive evaluation of ethnic diversity and support for multiculturalism will ensure a positive MCA, illustrating respect and understanding for the ethnic background of ethnic groups. On the other hand, a negative evaluation of ethnic diversity will ensure a negative MCA. We also used the Muslim attitude (MA) to examine the attitudes towards Muslims within the Belgium and the Dutch military organizations. As we will outlined later in this article, the attitude towards Muslims will be studied in this research as a special aspect of multiculturalism, because of recent societal developments in Western countries and missions of service members in Islamic countries. The term Muslim attitude is defined as the attitude towards a social group, in this case Muslims, or individual members in that social group (Strabac \& Listhaug, 2008).

\section{Acculturation Attitudes}

According to Berry et al. (1992) and Van de Vijver and Phalet (2004), diverse groups in society and in an organization are involved in a process of mutual adaptation described as acculturation: "those phenomena which result when groups 
of individuals having different cultures come into continuous first-hand contact, with subsequent changes in the original culture patterns of either or both groups" (Redfield, Linton, \& Herkovits, 1936, p. 149). Generally, members of different cultural groups have different attitudes towards the way in which the process of acculturation should take place. Despite the fact that the dominant group within an organization has more power and possibilities to decide how the subordinate group should adapt, the acculturation process often encompasses mutual influencing between the groups (Piontkowski, Florack, Hoelker, \& Obdrzálek, 2000). It is possible to distinguish several different strategies within acculturation, which can be measured on the basis of two dimensions (Berry, 1997). The first dimension comprises the importance attributed to the preservation of identity and characteristics, the second dimension the importance assigned to adaptation to the dominant culture (of the host ethnic culture). ${ }^{1}$ On the basis of these acculturation dimensions, four acculturation orientations can be measured. In figure one, these orientations are described from the perspective of the minority cultural groups (integration, separation, assimilation and marginalization) and from the perspective of the dominant majority cultural group (multiculturalism, pressure cooker, exclusion and segregation). In this research, we focus on the perspective of the dominant majority group. The first strategy is multiculturalism, which arises from the desirability to adapt to the dominant culture and, at the same time, preserve the ethnic cultural identity and characteristics. The second strategy, segregation, stems from the undesirability to adapt to the dominant culture and the desirability to preserve the cultural identity. The third strategy is called pressure cooker and arises from the desirability to adapt to the dominant culture and the undesirability to preserve identity and characteristics. The last strategy is exclusion, which comprises the undesirability to both adapt to the dominant culture and preserve the cultural identity and characteristics.

Maintenance of cultural identity and characteristics is considered to be of value

Adaptation to

dominant culture is

considered to be of value
INTEGRATION

multiculturalism

SEPARATION

segregation

\section{ASSIMILATION}

Pressure cooker

MARGINALIZATION

exclusion

Source: Richardson, Op den Buijs \& Van der Zee (2011)

Figure 1. Acculturation strategies for individuals and the larger society

Within the different dimensions, a further distinction can be made between private and public context. Andriessen and Phalet (2001) indicated that the norm of the dominant group is most prevalent in the public context, whereas in the private context the norms of the cultural minority groups are dominant. In concordance with this, the dominant group generally prefers cultural adaptation by cultural minorities in the public context, while at the same time ethnic minorities have the freedom to live their own cultural norms and values within the private context. And, if the dominant group is not open to a different culture in the public context, this can seriously threaten the identity of the minority, assuming that cultural groups often want to preserve their cultural norms and values in this public space (Taylor \& Moghaddam, 1994). Berry (1997) points out that the majority of cultural groups combine a positive attitude towards their own culture with a similarly positive attitude towards the dominant culture. This is associated with positive social adaptation (Van de Vijver \& Phalet, 2004).

\section{Influence of the Societal Context}

\subsection{Belgium}

Belgium can be labeled as a 'multicultural society'. As a result of successive immigration waves (FDS, 2012), first from the South of Europe (mid-twentieth century) and later from North-African or Sub-Saharan African countries (mid-sixties), Belgium counts nowadays a high percentage of foreigners ( $8.9 \%$ in 2007), mainly in Brussels ${ }^{2}$ (27.5\% versus $5.4 \%$ in Flanders and $9.2 \%$ in Wallonia) (Martiniello \& Perrin, 2009). But, contrary to the Netherlands, the

\footnotetext{
${ }^{1}$ In the Netherlands, the distinction between minority cultural groups on the one hand, and the majority (representatives of the dominant culture of the host nation) on the other, are normally described by means of the terms allochthonous and autochthonous. This paper will focus on the acculturation strategy that allochthonous people should follow according to autochthonous.

2 As capital of the European Union and host of several international institutions, Brussels has become a cosmopolitan and multicultural city where the use of English has progressively supplanted one of the two national language, i.e. Dutch
} 
Belgian colonial past did not have a large impact on those immigration waves as relatively few people have migrated from Congo, Burundi or Rwanda after the independence. If one adds to these foreigners Belgians who have received the Belgian nationality and Belgians who have at least one parent who is foreign-born, the proportion is even higher and reaches $19.4 \%$ of Belgium's total population (Centrum voor Gelijkheid van Kansen en voor Racismebestrijding, 2009). Contrary to a largely held perception, however, the important majority of the foreigners living in Belgium comes either from another EU country (Italy, France and The Netherlands occupying the top three positions), or from another industrial Western country. One should add that, in Belgium, it is far from easy to compare data on that matter as we have significant divergences between the two -Flemish and Walloon-linguistic communities on the implemented integration policies but also, on the used statistical categories (Jacobs \& Rea, 2006). Inspired by the French 'assimilationist-republican' model, the French-speaking side tends to deny the ethnic origin of immigrants and, using the distinction Belgians/ foreigners, tends in his policies to encourage newcomers to adopt the Belgian-French-speaking culture. Because of the Belgian history and the French-speaking domination during the past century, the Flemish side, however, is more similar to the Dutch 'multiculturalist' system where ethno-cultural minorities or "allochthonous" are recognized and supported (even if, in the Belgian - Flemish- case, there is no official recognition of some specific ethnic groups). As we see, both linguistic communities refer to separate classifications and accepted meanings which not only allow few academic assessments but also complicate the policy monitoring at the federal and regional level. Despite some obvious divides on other political-linguistic topics, the country found a consensus in April 2010 on Islamic face-covering veils. After Belgium's lower house of Parliament has -almost unanimously with 134 MPs in support of the law and two abstentions- voted for a law banning the burqa from all public venues, Belgium drew a huge international attention for being, at that time, the first European country initiating such a ban. Consequently, a strong signal was not only sent to Belgian's population but was also immediately heard by some Islamists who replied with a video posted on the Internet containing threats to attack the country. As the number of affected women remains very low, many comments reported that this law could primarily contribute to increase the "Islamophobia" among the country.

\subsection{The Netherlands}

Like her southern neighbor, also Dutch society can be marked as a 'multicultural' society. According to the most recent figures (CBS, 2012). 1.8 million people from ethnic minority groups live in the Netherlands. ${ }^{3}$ As a matter of fact, $40-50 \%$ of these minority groups is born in the Netherlands and can be defined as "second generation" ethnic minority. Dutch policy on ethnic minorities began in the early eighties, targeted on ethnic groups stemming from former colonies as the former Dutch West Indies (Indonesia) and the Caribbean (Surinam, and the Netherlands Antilles and Aruba) on the one hand, and those coming from Morocco and Turkey as a result of labor immigration on the other. Demographic prognosis already made clear that these ethnic groups were going to constitute a growing share of the Dutch population, as a dual effect of family-reunion and birthrate. In a near future, approximately $50 \%$ of the new generation from the most important economic region in the Netherlands (Amsterdam-Rotterdam-The Hague-Utrecht), will stem from ethnic minority group (CBS, 2012). Until 2001 relative few tensions and outbreaks were visible between ethnic groups in this expanding Dutch multicultural society. However, since September $11^{\text {th }} 2001$ serious tensions entered Dutch society, especially between majority allochtonous groups on the one hand and especially Dutch-Moroccan and Dutch-Turkish groups, but also Dutch-Antilles groups on the other. The murder of Dutch prominent politician Fortuyn in 2002 and of Dutch filmmaker Van Gogh in 2005, who both overtly critiqued Islamic religion, were the most obvious signs of these tensions. But also a Dutch 18 year old boy was beaten to death in Tilburg by a group of Dutch-Antilles youngsters in 2007 and serious tensions were visible in city districts with most Dutch Moroccan groups like in Gouda in 2009. These events gave rise to accentuating severe policy measurements in the media and politics against the weak societal position of ethnic minority groups and the growing criminality within this group. As a result, the Party For Freedom run by Geert Wilders, a political party that continuously accentuates problems society would have with Islam religion in general and with Islamic groups in particular, has become one of the most important political parties in the Netherlands, nowadays. On the other hand, ethnic minority groups, especially the youngsters amongst them, plead for a broad discourse in Dutch society on the topic of their backward labor market and educational position, integration and

\footnotetext{
3 An ethnic minority in the Netherlands ('Allochtoon') is defined as follows:

(a) A person born in Turkey, Morocco, Surinam, Netherlands Antilles, Aruba, former Yugoslavia, or other countries in South- or Central America, Africa or Asia with the exception of Japan and the former Dutch East Indies. Thus, people born after December 27th 1949 in Indonesia belong to the ethnic minority group.

(b) A person who can be found in the register, referred to as in article 1, of de Wet Rietkerk-payment.*

(c) Children of people denominated in $a$ and $b$.

* The Mollucan population group is included in this definition as well. Although they cannot be registered according to the principle of native country, they are included if they are entered in the register that has been used in the scope of the Wet Rietkerk- payment. This register recorded people who have been brought to the Netherlands in 1951 and 1952. Children of those registered are included in the definition as well.
} 
assimilation, the development of ethnic talents and strongly fight against "Islamic" stereotypes and criminalization of their group members. In this context, the Dutch Armed Forces generate their ethnic minority policy, while international pro-Al Qaeda groupings continue to threaten the Netherlands, if their Armed Forces are not withdrawn from Afghanistan. From this brief description of the two societal contexts, we see that both countries encountered similar tensions among their respective society and, even some obvious differences among what they called ethnic minorities, allochtonous or foreigners, multiculturality remains a huge challenge on both side of the border. What we also note is that, since the last decades, the observed tensions tend to refer mainly to the integration of Muslims, even if the percentage of Muslims living in Belgium (3.6\%) remains lower than in the Netherlands (5.8\%). After depicting the theoretical framework in the next section, we will see if these tensions tend to lead to negative attitudes among Defence organizations and if these trends could be amplified in traditionally homogeneous workplaces.

\section{Methods}

\subsection{Procedures}

At the end of June 2008, a large survey ( $\mathrm{N}=4105)$ among employees of the Dutch Defence organization was conducted. In an introductory letter, the respondents were informed that the purpose of this research was about cultural diversity within the Dutch Defence organization and that their anonymity would be guaranteed. In total, $12 \%$ filled out the reason for not responding, entering "lack of time" as the main reason. A total of 1290 questionnaires (31\%) were returned (see appendix A for the demographics). Most of the respondents were male (87\%), service member (62\%), 36 years of age or older (66\%) and had been working for the Dutch Armed Forces for 15 years or more. A certain amount has an education on the middle level (46\%) and was employed in the Royal Netherlands Army (29\%). Regarding the ranks, Non-Commissioned Officers and Officers represented respectively $26 \%$ and $22 \%$ of total sample size. About a third of the service members had not participated in military operations abroad (37\%) and most of the Dutch respondents were 45 years or older (44\%). In total, 5.3\% of all the respondents had an ethnic-cultural, 'allochtonous' background.

In Spring 2009, the Dutch Secretary of State for Defense asked his Belgian colleague, Pieter De Crem, the Defense Minister, to replicate the Dutch survey in Belgium. In light of the strong cooperation between the two organizations (among other in the Navy), Pieter De Crem accepted the request and asked the Department of Behavioral Sciences of the Royal Military Academy in Brussels to carry out the survey. To that end, 1200 Belgian military and civilian personnel were selected using a two-stage non probability cluster (main military bases) sampling frame with quota variables. The quota variables were: language, service, grade, civilian/military statute.

Of the 1200 questionnaires distributed in the selected units, 1183 were sent back duly completed ( $99 \%$ ), a very high rate for this kind of survey. Not surprisingly, the resulting sample of 1183 was found to be fairly representative of the parent population on the quota variables (see appendix B for the demographics). Most of the respondents were male $(89 \%)$, service member (94\%), volunteer (45\%) or Non-Commissioned Officer (38\%), 36 years of age or older (59\%), Dutch speaking (55\%) and had been moderately educated (55\%). Except for sex, the Belgian and Dutch samples differ significantly concerning their representation of each of the socio-demographic variables presented in the table 1 below. This is particularly the case regarding the age and the rank of respondents, as we see that Dutch militaries represented in the sample are older and more high-ranking than their Belgian counterparts. Consequently, the education level is also higher on the Dutch side.

Table 1. Demographics of the Belgian and the Dutch respondents (\%)

\begin{tabular}{llllll}
\hline Sex & Male & $\begin{array}{l}\text { Belgium } \\
\text { (\% response) }\end{array}$ & $\begin{array}{l}\text { Netherlands } \\
\text { (\% response) }\end{array}$ & T-value & T-Sig. \\
Age & Female & 89 & 87 & -1.59 & .11 \\
& $\mathbf{2 5}$ or younger & 11 & 13 & -3.98 & .000 \\
& $\mathbf{2 6 - 3 5}$ & 27 & 16 & & \\
Rank & $\mathbf{3 6}-\mathbf{4 5}$ & 29 & 18 & & .000 \\
& $\mathbf{4 5}$ or older & 30 & 22 & -6.03 & \\
& Volunteer & 45 & 44 & & .000 \\
Education & NCO & 38 & 14 & & \\
level & Officer & 12 & 26 & -4.48 & \\
& Civilian & 6 & 22 & & \\
\hline
\end{tabular}

\subsection{Instruments}

In order to allow comparisons, the Belgian questionnaire consisted, for a part, of the same questions than those of the Dutch survey. The other part was made up of specific questions on the diversity policy within the Belgian Defense 
department and on the national identity of Belgian respondents. First of all, in order to measure the attitude towards multiculturalism, both surveys made use of the Multicultural-attitude Scale. This scale is based on the Canadian Multicultural Ideology Scale (Berry \& Kalin, 1995) and contains both negatively and positively formulated items. The original scale contains 15 items, to which participants could respond using a 5-point Likert scale. Native English speakers at the Netherlands Defence Academy translated this scale into Dutch (Bosman, Richardson \& Soeters, 2007). And, for the French-speaker Belgians, the items have been translated into French by bilingual and originally native French speakers. This translation has also been used in the current research. Some examples of items on this scale are: "A society that has a variety of ethnic and cultural groups is more able to tackle new problems as they occur" or "Dutch people should do more to learn about the customs and heritage of different ethnic and cultural groups in this country". On the basis of a reliability analysis 3 items were excluded from further analysis, resulting in a reliability of the final 12 -item scale of Cronbach's alpha $=.82$ for the Dutch sample and Cronbach's alpha $=.81$ for the Belgian sample.

Secondly, as an indicator to measure Muslim-attitudes, both surveys used a scale developed by Pettigrew, Christ, Wagner and Stellmacher (2007). This scale includes 4 items on a 5-point Likert scale ranging from 1 (completely disagree) to 5 (completely agree) and contains both negatively and positively formulated items. However, since in Belgium one of the 4 original items wasn't included in the questionnaire, this comparative analysis will present, for both countries, the scores on 3 items. Again, this scale was translated into Dutch in close collaboration with English native speakers of the Netherlands Defence Academy $(\alpha=.75)$, while for the French-speaker Belgians, the items were translated into French by bilingual and originally native French speakers $(\alpha=.71)$. The three items on this scale are: "Are there so many Muslims here that you sometimes feel like a stranger in your own country?", "People's trust with respect to Muslims is justified", and "Muslim culture is compatible with the culture of the Western world".

Lastly, to measure the attitude towards acculturation, both surveys used a scale developed by Andriessen and Phalet (2002) which is a 4-item scale with 5 response options ranging from 1 (completely disagree) to 5 (completely agree). This scale measures acculturation in both the private as well as the public context. Combining answers two-by-two led to a matrix with four options based on the two basic dimensions (cultural maintenance and cultural adaptation) as proposed by Berry (1997). As with the other scale, this one was also translated into Dutch in close collaboration with native English speakers of the Netherlands Defence Academy (Bosman, Richardson \& Soeters, 2007).

Examples of item on this scale are: "Ethnic minorities should maintain their ethnic culture in the private context (for instance at home)" or "Ethnic minorities should adapt themselves to the Dutch culture and society in the public context (for instance at school or at work)". ${ }^{4}$

\section{Results}

\subsection{Multicultural Attitude}

Bivariate analysis of the nationality - Belgian or Dutch- of respondents and their position on the MCA-scale reveals a small but statistically significant $(\mathrm{F}=155.211 ; \mathrm{p}<.000)$ difference between multicultural attitudes of Dutch and Belgian Defense employees, with the latter scoring slightly below $(-.18 \sigma)$ and the former slightly above $(+.16 \sigma)$ average $(M=2.85)$. These scores indicate that Dutch Defense employees have a more 'neutral' $(M=3.01)$ attitude toward ethnic cultural minorities than their Belgian colleagues, who display a slightly 'negative' $(\mathrm{M}=2.68)$ multicultural attitude. ${ }^{5}$

Table 2. Multicultural-attitude scale by nationality

\begin{tabular}{llll}
\hline \multicolumn{4}{l}{ MCA-scale by nationality $(\mathrm{eta}=.246)$} \\
\hline & $\mathrm{N}$ & Mean & Deviation \\
Belgium & 1145 & 2.68 & -.177 \\
Netherlands & 1269 & 3.01 & +.160 \\
\hline ALL & 2414 & 2.85 & \\
\hline
\end{tabular}

While the nationality of respondents only explains a small proportion (6\%) of total MCA-scale variance, ${ }^{6}$ other background variables such as rank and education level might contribute to the further explanation of MCA-scale scores.

\footnotetext{
${ }^{4}$ For making comparisons between the Belgian and the Dutch survey, one limitation will be linked to the fact that we did not always use the same terminology. Some items have been slightly modified and adapted in accordance with the Belgian terminology. In that regard, for the Belgian case, we have not used the category "ethnic minorities", but those of general application in the Belgian Defence (i.e. "Belgians of foreign origin" or "people from different ethnic origins") and in the societal context (i.e. "autochthonous" and "allochthonous") which can be more restrictive and therefore induce some slight changes in the perception of respondents regarding the items.

${ }^{5}$ Mean scores on a Likert scale with 5 response categories: $1=$ completely disagree, $2=$ rather disagree, $3=$ neutral, $4=$ rather agree, $5=$ completely agree.

${ }^{6}$ Correlational strength is rather moderate (eta $=.246 ; \mathrm{r}^{2}=\mathrm{eta}^{2}=.06$ ).
} 
A model which examines the interrelationship between "nationality', 'rank' ${ }^{7}$ and 'multicultural attitudes', produces a proportion of $8,4 \%$ of total MCA-scale variance explained. Eta-coefficients indicate that, in a bivariate analysis, 'rank' (.239) can explain about as much MCA-scale variance as 'nationality' (.246). However, when controlling the effects of both independent variables in a multivariate model, explicative powers of both 'nationality' (beta=.188) and, even more so, 'rank' (beta=.164) decline. This is most likely caused by differences in sample composition: the Belgian sample distribution of respondents' rank is representative for the Belgian Defence as a whole, representing large groups of volunteers (45\%) and NCO's (38\%), whereas the Dutch sample over represents civilian employees (38\%) and officers $(22 \%)$, and highly underrepresents volunteers (14\%). Still, after controlling the effects of both independent variables, both 'nationality' $(F=71.072 ; p<.000)$ and ' $r a n k '(F=20.406 ; p<.000)$ remain to have a significant effect (beta values above) on the multicultural attitudes of respondents. Dutch respondents $(+.122 \sigma)$, officers $(+.207 \sigma)$ and civilian Defense employees $(+.065 \sigma)$ score above average on the MCA-scale and have a more or less neutral attitude toward multiculturalism, whereas Belgian respondents (-.136 $)$, NCO's $(-.063 \sigma)$ and volunteers $(-.106 \sigma)$ have a more negative multicultural attitude. The effect of respondents' rank is also consistent across both countries, given the fact that the interaction of 'nationality' and 'rank' is not significant $(\mathrm{F}=0.335 ; \mathrm{p}>.05)$.

Table 3. Multicultural-attitude scale by nationality and rank

\begin{tabular}{lllll}
\hline \multicolumn{1}{l}{ MCA-scale by nationality (eta=.246; beta= } & 188) and rank (eta=.239; beta=.164) \\
\hline \multirow{4}{*}{ Nationality } & $\mathrm{N}$ & $\begin{array}{l}\text { Mean } \\
\text { (adjusted for factors) }\end{array}$ & $\begin{array}{l}\text { Deviation } \\
\text { (adjusted for factors) }\end{array}$ \\
& & & 2.72 & -.136 \\
\multirow{3}{*}{ Rank } & Belgium & 1127 & 2.98 & +.122 \\
& Netherlands & 1264 & 2.85 & \\
& ALL & 2391 & 2.06 & +.063 \\
& Officers & 407 & 3.06 & -.106 \\
\hline & NCO & 758 & 2.79 & +.065 \\
\hline
\end{tabular}

In addition to the model in table 3, respondents' level of education has a significant impact on multicultural attitudes as well. What is more, when 'education' is taken into account, explicative power of 'rank' almost evaporates (eta=.235; beta $=.070$ ), which isn't surprising since, in a general way, higher levels of education have been mostly obtained by higher ranked military personnel (and some civilian employees). However, because of the disproportionately large number of Dutch respondents with a higher level of education, beta-coefficients of 'education' (eta=.221; beta=.161) and 'nationality' (eta=.244; beta=.205) also decline, as was the case when controlling 'rank' for the effect of 'nationality'. Nevertheless, this model, which combines the effects of 'nationality' $(\mathrm{F}=85.057$; $\mathrm{p}<.000)$, 'education level' $(\mathrm{F}=23.585 ; \mathrm{p}<.000)$ and 'rank' $(\mathrm{F}=2.814 ; \mathrm{p}<.05)$, can explain a proportion of $10 \%$ of MCA-scale variance.

Table 4. Multicultural-attitude scale by nationality, rank and education level

\begin{tabular}{|c|c|c|c|c|}
\hline \multicolumn{5}{|c|}{ MCA-scale by nationality $(\mathrm{eta}=.244 ;$ beta $=.205)$ rank $(\mathrm{eta}=.235$; beta=.070) education level $(\mathrm{eta}=.221$; beta $=.161$} \\
\hline \multirow{4}{*}{ Nationality } & & $\mathrm{N}$ & $\begin{array}{l}\text { Mean } \\
\text { (adjusted for factors) }\end{array}$ & $\begin{array}{l}\text { Deviation } \\
\text { (adjusted for factors) }\end{array}$ \\
\hline & Belgium & 1113 & 2.70 & -.147 \\
\hline & Netherlands & 1213 & 2.99 & +.135 \\
\hline & ALL & 2326 & 2.85 & \\
\hline \multirow[t]{2}{*}{ Rank } & Officers & 407 & 2.95 & +.098 \\
\hline & $\mathrm{NCO}$ & 758 & 2.83 & -.023 \\
\hline \multirow{5}{*}{ Level of education } & Volunteers & 680 & 2.81 & -.043 \\
\hline & Civilians & 546 & 2.87 & +.015 \\
\hline & Low & 595 & 2.74 & -.107 \\
\hline & Middle & 1169 & 2.81 & -.037 \\
\hline & High & 562 & 3.04 & +.189 \\
\hline
\end{tabular}

Other background variables, such as respondents' age and sex, do not add significantly to the model presented above. While, among the variables that were tested, the nationality of respondents proved to offer the strongest explanation of differing multicultural attitudes, the overall importance of respondents' nationality is rather limited: when controlling for the effects of 'education' and 'rank', being a Belgian or a Dutch national can only account for about $4 \%$ of MCA-scale variance.

\footnotetext{
7 The variable 'rank' was recoded to include four categories: officers, non-commissioned officers, volunteers and civilian employees.
} 


\subsection{Muslim Attitude}

Nationality seems to have a certain effect $(\mathrm{F}=198.875 ; \mathrm{p}<.000)$ on respondents' Muslim attitudes and could explain about $8 \%$ of MA-scale variance. Again, contrary to their Dutch $(\mathrm{M}=3.10 ;+.258 \sigma)$ colleagues, Belgian $(\mathrm{M}=2.60 ;-.282 \sigma)$ Defense employees score slightly below mid-point ( $\mathrm{M}=2.88)$ (see table 5).

Table 5. Muslim-attitude scale by nationality

\begin{tabular}{lccl}
\hline \multicolumn{4}{l}{ MA-scale by nationality $(\mathrm{eta}=.274)$} \\
Belgium & $\mathrm{N}$ & Mean & Deviation \\
Netherlands & 1172 & 2.60 & -.282 \\
\hline ALL & 1281 & 3.10 & +.258 \\
\hline
\end{tabular}

As observed for MCA-scale scores, 'rank' $(\mathrm{F}=10.867 ; \mathrm{p}<.000)$ and 'education level' $(\mathrm{F}=12.527 ; \mathrm{p}<.000)$ have some impact on respondents' Muslim attitude as well, in addition to the effect of their nationality $(F=105.824 ; p<.000)$. Dutch respondents $(+.214 \sigma)$, officers $(+.280 \sigma)$ and the highly educated $(+.198 \sigma)$ score above mid-point, displaying a more or less 'neutral' Muslim attitude. When combined, these three variables can explain almost $12 \%$ of MA-scale variance (see table 6):

Table 6. Muslim-attitude scale by nationality, rank and education level

\begin{tabular}{|c|c|c|c|c|}
\hline \multicolumn{5}{|c|}{ MA-scale by nationality $(\mathrm{eta}=.267$; beta $=.226)$ rank $(\mathrm{eta}=.265$; beta=.130) education level $(\mathrm{eta}=.208$; beta=.116) } \\
\hline \multirow{3}{*}{ Nationality } & & $\mathrm{N}$ & $\begin{array}{l}\text { Mean } \\
\text { (adjusted for factors) }\end{array}$ & $\begin{array}{l}\text { Deviation } \\
\text { (adjusted for factors) }\end{array}$ \\
\hline & Belgium & 1138 & 2.65 & -.231 \\
\hline & Netherlands & 1225 & 3.09 & +.214 \\
\hline \multirow{3}{*}{ Rank } & ALL & 2363 & 2.88 & \\
\hline & Officers & 387 & 3.16 & +.281 \\
\hline & $\mathrm{NCO}$ & 756 & 2.83 & -.049 \\
\hline \multirow{5}{*}{ Level of education } & Volunteers & 687 & 2.78 & -.094 \\
\hline & Civilians & 533 & 2.87 & -.013 \\
\hline & Low & 609 & 2.78 & -.103 \\
\hline & Middle & 1186 & 2.84 & -.042 \\
\hline & High & 568 & 3.08 & +.198 \\
\hline
\end{tabular}

In accordance with the analysis of MCA-scale scores, respondents' age and sex do not add significantly to the model presented above. The 'nationality' (beta=.226) and 'rank' (beta=.130) variables, however, explain slightly larger proportions of variance in this analysis of Muslim attitudes, while the level of education of respondents is less influential (beta=.116).

\subsection{Acculturation Attitude}

Table 7 shows the preferences of Belgian and Dutch Defense employees for each of four acculturation strategies (multiculturalism, pressure cooker, segregation and exclusion) in a private context, cross-tabulating the answers of respondents on two question-items, namely 'Ethnic minorities should be able to maintain their ethnic cultures in private life (f.i. at home)' and 'In their private lives (f.i. at home), ethnic minorities should adapt to Belgian/Dutch culture and society'. Results indicate that Belgian (32\%) and Dutch (49\%) Defense employees clearly prefer the segregation strategy for ethnic minorities in a private context. Belgian Defense employees (33\%) are, however, more often than their Dutch (23\%) colleagues, in favor of an adaptation of ethnic minorities to the dominant culture and, even more visible, Dutch employees dot not prefer adaptation, while only $38 \%$ of the Belgian employees choose for non-adaptation.

Table 7. Private context acculturation strategies by nationality

\begin{tabular}{clllll}
\hline \multicolumn{1}{l}{ Private context acculturation strategies $(\%)$} \\
\hline
\end{tabular}

In a public context, however, Belgian and Dutch respondents are much more likely to stress the need for ethnic minorities to adapt to the dominant culture. Table 8, which cross-tabulates responses on the question-items 'Ethnic minorities should maintain their own culture in public life (e.g. at work)' and 'In public life (e.g. at work), ethnic minorities should adapt to Belgian/Dutch culture and society', reveals a large majority of Belgian (61\%) and Dutch 
(65\%) Defense employees in favor of the pressure cooker strategy. Only one in ten (B: 9\% and NL: 12\%) believes ethnic minorities should maintain their own culture in a public context.

Table 8 . Public context acculturation strategies by nationality

Acculturation in public context (\%)

\begin{tabular}{|c|c|c|c|c|c|c|c|c|c|}
\hline & & \multicolumn{8}{|c|}{ Maintenance of cultural identity and characteristics is considered to be of value } \\
\hline \multirow{6}{*}{$\begin{array}{c}\text { Adaptation to } \\
\text { dominant culture is } \\
\text { considered to be of } \\
\text { value }\end{array}$} & & Yes & & No & & Neu & & Tota & \\
\hline & & B & NL & B & NL & B & NL & B & NL \\
\hline & Yes & 6 & 9 & 61 & 65 & 13 & 10 & 80 & 84 \\
\hline & No & 2 & 2 & 2 & 3 & 2 & 2 & 6 & 7 \\
\hline & Neutral & 1 & 1 & 3 & 3 & 10 & 5 & 14 & 9 \\
\hline & Total & 9 & 12 & 66 & 71 & 25 & 17 & 100 & 100 \\
\hline
\end{tabular}

\section{Conclusion and Discussion}

We compared the Netherlands and Belgium on the 'multicultural dimension' of cultural diversity. This means as that we focused on the multicultural attitude, the Muslims attitude and the acculturation orientation of Dutch and Belgian employees in the military. From this comparative analysis of Belgium and the Netherlands, it appears that there is a small but significant difference in scores on the Multicultural attitude and Muslim attitude. The scores indicate that Dutch Defence employees had a more 'neutral' attitude toward ethnic cultural minorities and Muslims than their Belgian colleagues, who displayed a slightly 'negative' attitude on both aspects. Moreover, the nationality of both respondents proved to offer the strongest explanation of different attitudes, however the overall importance of respondents' nationality was rather limited. These results are comparable with studies of Verkuyten, Hagendoorn \& Masson (1996) and Gijsbers (2005). It appears that the majority of native Dutch inhabitants judge the Moroccan, (Muslim) Dutch the least positive, followed by the Antillean Dutch and the Turkish (Muslim) Dutch (Bosman, 2008). The difference between the more or less 'neutral' judgements of the native Dutch and the 'negative' judgements of native Belgian could be explained by the comparative grid/group analysis of Soeters \& Van der Meulen (1999). This analysis was based on the degree of which Western countries differ in their scores on 'cultural diversity and separation'. As a result of this analysis, the Belgian and Dutch Defence organisations occupied opposite positions in their scores. The Dutch showed some group distinction on 'cultural diversity and separation', while Belgium, on the contrary, had a strong group distinction, notably exemplified by a strong separation regarding its language groups. This could be historically related with the longer tradition of the Netherlands when dealing with non-European migrants and immigrants from Muslims countries (Richardson \& Bosch, 1999). The Netherlands dealt with lots of former (Muslim) colonies until recently. ${ }^{8}$ It could be argued that the Dutch had some experience in issues about immigration and integration of ethnic minorities and Muslims. Nevertheless, in Europe, the attitude towards multiculturalism in general and Muslims in particular in both countries are under tensions since the 90's of the former century, also politically (Coenders, Lubbers and Scheepers, 2003; Amnesty International, 2012). Citizens no longer share the same cultural, religious and ethnic background, but belong to different and even competing value patterns. Resistance against this 'multiculturalism is more visible and not just to ignore (Van Leeuwen \& Van Tinnevelt, 2005).

The results on the acculturation strategies show that military organisations in Belgium and the Netherlands do not really support a nulticulturalism perspective, as defence employees show a clear preference for the segregation strategy in the private, and for the pressure cooker strategy in the public domain. Some differences are also obvious, the Belgian military employees are far more in favour of adaptation of the dominant culture of ethnic cultural minorities than the Dutch. This result might be clarified by the 'integrated threat theory' of Stephan and Stephan (1996) in combination with Allport's contact hypothesis (1958). In the private domain, the dominant cultural group is scarcely in contact or conflict with minority cultural groups and, as a result, they dominant group would not often experience feelings of realistic threat. In the public domain, however, dominant and minority groups have more contact with each other. These contacts might even lead to antagonist relationships: 'Contact in a hierarchical social system, or between people who equally lack status ...., or contacts between individuals who perceive one another as threats, are harmful rather than helpful, (Allport, 1958, p. 453). In a hierarchical, traditional command system like the military, this could be the situation. The dominant cultural group could feel realistic threat and anxiety towards unknown cultural habits and values of minority groups, and, as a result could require the minority groups to adapt to the existing standards (Stephan \& Stephan, 1996). In this context, it could be interesting to explain the differences between the military organizations in

\footnotetext{
${ }^{8}$ Indonesia (from 1798 until 1949), Surinam, (from 1667 until 1975), Aruba (from 1636 until 1986), Curacao (from 1791 until 2010), St. Maarten (from 1648 until 2010) and Saba, St. Eustatius and Bonaire (until now).
} 
both countries on the bases of societal differences level like stability of democracy and ratings of integration policy (Bourhis, Moïse, Perreault, \& Senécal, 1997) or societal values (Breughelmans, Van de Vijver \& Schalk-Soekar, 2007).

It also appears in the results that the Belgian employees are more neutral towards their climate, while the Dutch are slightly positive towards it. This could be explained by the fact that the implementation of the Dutch defence diversity policy is much more developed than in Belgium. Started in 1997 as "emancipation policy", the Dutch ministry of defence, however often troublesome and stopped in 2012, developed a "Gender and Diversity" policy in 2008 (Richardson, 2010). The Belgian, however, started a diversity policy in 2003. One could imagine that the communication and implementation of central issues of the diversity policy in Belgium is not yet developed as it is in the Netherlands. As a result, Belgian employees could less be able to see results of the ministry's policy in their working environment as the Dutch could see them. Lastly, the perception of the direction of the diversity policy is quite the same in Belgium and the Netherlands. Both accentuate the deficit approach followed by the prejudice and the differentiation approach in their perception of the direction of the diversity policy the ministries should make predominant. This reflects the results on the acculturation strategies; employees in both military organisations accentuate the adaptation to the dominant culture in the public domain. The responsibility for this adaptation, however, is laid by the cultural minorities themselves; they must follow courses and training sessions to reach the level that the native Dutch and Belgian have reached. This means that diversity policy should, in first instance, be focussed on the delays cultural minority groups must make up.

\section{References}

Amnesty International. (2012). Choice and prejudice: Discrimination against Muslims in Europe. Amnesty International: Index: EUR 01/001/2012.

Allport, G.W. (1958). The Nature of Prejudice. A comprehensive and penetrating study of the origin and nature of prejudice. New York: Anchor Books.

Andriessen, I., \& Phalet, K. (2002). Acculturation and school success: a study among minority youth in the Netherlands. Intercultural Education, 13 (I), 21-36.

Arends-Tóth, J.V., \& van de Vijver, F.J.R. (2003). Multiculturalism and acculturation: Views of Dutch and Turkish-Dutch. European Journal of Social Psychology, 33, 249-266.

Avery, D.R., McKay, P.F., Wilson, D.C., \& Tonidandel, S. (2007). Unequal attendance: The relationship between race, organizational diversity cues and Absenteeism, Personnel Psychology 60 , 875-902.

Beck, U. (2002). The cosmopolitan society and its enemies. Theory, culture and society, 19, 17-44.

Berry, J.W. (2005). Acculturation: living successfully in two cultures. International Journal of Intercultural Relations, $29,697-712$.

Berry, J. W. (1997). Lead article Immigration, Acculturation and Adaption. Applied Psychology: An International Review, 46, 5-68.

Berry, J.W., \& Kalin, R. (1995). Multicultural and ethnic attitude in Canada: an overview of the 1991 national survey. Canadian Journal of Behavioral Science, 27, 301-320.

Berry, J. W., Poortinga, Y. H., Segall, M. H., \& Daren, P. R. (1992). Cross cultural psychology. Research and Applications. Cambridge: Cambridge University Press.

Bosman, F., Richardson, R., \& Soeters, J. (2007). Multicultural tensions in the military? Evidence from the Netherlands Armed Forces. International Journal of Intercultural Relations 31,3, 339-362.

Bosman, F. (2008). Uniformed Diversity. A multifaceted approach towards the diversity climate in the Netherlands defense organization. Tilburg: Tilburg University Press.

Bourhis, R.Y., Moïse, L.C., Perreault, S., \& Senécal, S. (1997). Towards an Interactive Acculturation Model: A Social Psychological Approach, International Journal of Psychology 32, 6, 359-386.

Breughelmans, S.M., Van de Vijver, F.J., \& Schalk-Soekar, S.G.S. (2009). Stability of Majority Attitudes toward Multiculturalism in the Netherlands between 1999 and 2007. Applied Psychology 58, 4, 653-671.

Brubaker, R. \& Cooper, F. (2000). Beyond identity. Theory and Society 29 (1), 1-47.

CBS (2012). Jaarrapportage Integratie report [Annual Integration report 2012]. The Hague: CBS.

Centrum voor Gelijkheid van Kansen en voor Racismebestrijding (2009). Migraties en migrantenpopulaties in België [Migrations and Migrant populations in Belgium]. Brussels: CGKR.

Coenders, M., Lubbers, M., \& Scheepers, P. (2003). Majority populations' attitudes towards migrants and minorities. Report for the Eropean Monitoring centre on Racism and Xenophobia. (NO 2003/04/01). 
Cox, T. (1994). Diversity in Organizations, theory, research and practice. San Francisco: Berrett-Koehler publishers Inc.

Dansby, M.R., Stewart, J.B., \& Webb, S.C. (2001, Eds.). Managing diversity in the military. Research perspectives from the defense equal opportunity management Institute. New Brunswick: Transaction Publishers.

Dansby, M. \& Landis, D. (1996). Intercultural training in the military. In D. Landis \& R.S. Bhagat, Handbook of international training $\left(2^{\text {nd }}\right.$ edition), Thousand Oaks: Sage, $203-216$.

FPS Economy (2012). Directorate- general Statistics and Economic Information, Service Demography. Brussels. (http://www.statbel.fgov.be).

Ely, R.J., \& Thomas, D.A. (2001). Cultural diversity at work: The effects of diversity perspectives on work group processes and outcomes. Administrative Science Quarterly, 46,2, 229-273.

Gijsbers, M. (2005). Opvattingen van autochtonen over de multi-etnische samenleving. (views of native Dutch and ethnic minorities on the Multi-ethnic society). In SCP, WODC \& CBS (Eds.), Jaarrapport Integratie 2005 (annula report Integration 2005) (PP. 189-205). Den Haag, Voorburg: SCP, WODC, CBS.

Hooghe, M., Reeskens, T., Stolle, D., \& Trappers, A. (2006). Ethnic diversity, trust and ethnocentrism and Europe. A multilevel analysis of 21 European countries. Paper presented at the $102^{\text {nd }}$ annual meeting of the APSA, Philadelphia, August 31-September 3, 2006.

Hooghe, M. (2006). The challenge of diversity: different answers and solutions,In L. d'Haenens, M. Hooghe, D. Vanheule \& H. Gezduci (Eds.) New citizens, new policies? Developments in diversity policy in Canada and Flanders, Ghent, Academia press, 3-10.

IPSOS (2009). Sondage: Dans quelle mesure les Belges sont-ils tolérants par rapport aux minorités ethniques? [Survey : To what extent are Belgians tolerant regarding ethnic minorities?] Brussels: IPSOS, technical report.

Jacobs, D., \& Rea, A. (2006). Construction and import of ethnic categorizations: "allochtones" in the Netherlands and in Belgium. Conference Paper, EURODIV conference, Milano.

Moskos, C.C., \& Butler, J.S. (1996). All That We Can Be: Black Leadership and Racial Integration The Army Way. New York: Basic Books.

Kruithof, H. (2001). Multiculturele persoonlijkheidseigenschappen en effectiviteit van allochtone medewerkers in de Nederlandse werkorganisatie [Multicultural personality and effectivity of allochthonous employees in Dutch Labour Organizations]. Master thesis, Groningen, University of Groningen.

Liu, S. (2007). Living with others: Mapping the routes to acculturation in a multicultural society. International Journal of Intercultural Relations 31, 6, 761-778.

Manigart, P., \& Resteigne, D. (2013). Sortir du rang : la gestion de la diversité à la Défense Belge [Exit Row the management of diversity at the Belgian defence]. Brussels: L'Académie en poche.

Martiniello, M., \& Perrin, N. (2009). Immigration et diversité en Belgique. [Immigration and diversity in Belgium]. In J. Beaufays \& G. Matagne (2009) La Belgique en mutation: Systèmes politiques et politiques publiques (1968-2008) [Belgium in mutation : Political systems and public policies (1968-2008), Brussels: Bruylant,217-251.

Miller, L., \& Moskos, C. (1995). Humanitarians or Warriors? Race, gender, and combat status in operation 'Restore Hope'. Armed Forces \& Society, 21, 4, 615-637.

Pettigrew, T.F., Christ, O., Wagner, U., \& Stellmacher, J. (2007). Direct and indirect intergroup contact effects on prejudice: a normative interpretation. International Journal of Intercultural relations, 31, 411-425.

Piontkowski, U. Florack, A., Hoelker, P., \& Obdrzálek, P. (2000). Predicting acculturation-attitudes of dominant and non-dominant groups. International Journal of Intercultural Relations, 24, 1-26.

Putnam, R.D. (2007). E Pluribus Unum: diversity and community in the twenty-first century. The 2006 Johan Skytte prize lecture. Scandinavian Political Studies, 30, 137-174.

Redfield, R., Linton, R., \& Herkovits, M. J. (1936). Memorandum for the study of acculturation. American Anthropologist, 38, (1), 149-152.

Resteigne, D., \& Soeters, J. (2010). Différenciation culturelle et stratégies de coopération en milieux militaires multinationaux. Cultures \& Conflits, 77, 59-76.

Richardson, R., \& Bosch, J. (1999). The Diversity Climate in the Dutch Armed Forces. In J. Soeters \& J. van der Meulen (1999, Eds.). Managing Diversity in the Armed Forces. Tilburg: TUP, 127-155.

Richardson, R. (2010). Recruitment and Retention of Ethnic Cultural Minorities in the Dutch Armed Forces. In T. S. 
Tresch \& C. Leuprecht. (2010, Eds.). Europe Without Soldiers? Recruitment And Retention Across The Armed Forces Of Europe. Montreal, Kingston \& London: McGill-Queen's University Press, 21-35.

Richardson, R., Op Den Buijs, T., \& Van der Zee, K. (2011). Changes in Multicultural, Muslim and Acculturation attitudes in the Netherlands armed forces. International Journal of Intercultural Relations, 35, 580-591.

Quillian, L. (1995). Prejudice as a response to perceived group threat: Population composition and anti-immigrant and racial prejudice in Europe. American Sociological Review 60,4, 586-611.

Scoppio, G. (2009). Diversity best practices in military organizations in Canada, Australia, the United Kingdom, and the United States. Canadian military journal 9,3, 17-30.

Soeters, J. \& Van der Meulen, J. (1999). Managing diversity in the armed forces. Experiences from nine countries. Tilburg University Press.

Soeters, J. \& Van der Meulen, J. (2007, Eds.). Cultural diversity in the Armed Forces: An international comparison. London: Routledge.

Stephan, W.G., \& Stephan, C.W. (1996). Predicting prejudice. International Journal of Intercultural relations, 20(3/4), 409-426.

Strabac, Z., \& Listhaug, O. (2008). Anti-Muslim prejudice in Europe: A multilevel analysis of survey data from 30 countries. Social Science Research, 37, 268-286.

Taylor, M. D., \& Moghaddam, F. M. (1994). Theories of Intergroup Relations: International Social Psychological Perspectives. Westport: Praeger Publishers.

Van de Vijver, F. J. R., \& Phalet, K. (2004). Assesment in multicultural groups: The role of acculturation. Applied Psychology: An International Review, 53, 215-223.

Van der Meulen, J, \& Soeters, J. (2007). Introduction. In J. Soeters \& J. van der Meulen (Eds.) Cultural diversity in the Armed Forces: An international comparison, London: Routledge. 1-14.

Van Leeuwen, B., \& Van Tinnevelt, R. (2005, Eds.). De Multiculturele Samenleving in Conflict: Interculturele spanningen, Multiculturalisme en Burgerschap. [The Multicultural Society: Intercultural tensions, Multiculturalism and Citizenship]. Leuven: Acco.

Verkuyten, M., Hagendoorn, L., \& Masson, K. (1996). The Ethnic Hierarchy Among Majority and Minority Youth in The Netherlands. Journal of Applied Psychology, 26(12), 1104-1118.

Winslow, D., \& Dunn, J. (2002). Women in the Canadian Forces: Between legal and social integration. Current Sociology 10, 5, 641-667.

Wolff, S. (2008). Ethnic minorities in Europe: the basic facts. Report prepared for a workshop at the European Centre for Minority Rights, Center for the International Crisis Management and Conflict Resolution, University of Nottingham, UK.

\section{$(\mathrm{cc}) \mathrm{BY}$}

This work is licensed under a Creative Commons Attribution 3.0 License. 